\title{
Crystal Structure of a 1:1 Complex of Palmitic acid and Nicotinamide
}

\author{
Makoto Amai, Masayuki KamiJo, Hiromasa NagaSe, Noriko Ogawa, Tomohiro Endo, and \\ Haruhisa UEDA ${ }^{\dagger}$
}

Department of Physical Chemistry, Hoshi University, 2-4-41 Ebara, Shinagawa-ku, Tokyo 142-8501, Japan

\begin{abstract}
An equimolar mixture of palmitic acid (hexadecanoic acid) and nicotinamide (3-pyridinecarboxamide) in acetone yielded crystals of a 1:1 complex, $\mathrm{C}_{22} \mathrm{H}_{38} \mathrm{~N}_{2} \mathrm{O}_{3}$. Palmitic acid forms a lipid bilayer and is stacked to form a lamellar structure. The alkyl chain of palmitic acid has an all-trans conformation. Nicotinamides form a dimmer, which is intercalated into hydrophilic regions of the lamellar structure.
\end{abstract}

(Received December 9, 2005; Accepted February 24, 2006; Published on web May 19, 2006)

Nicotinamide (NA) is mainly used to treat pellagra disease. It is known that normal saturated fatty acids (FA) of $\mathrm{C}_{12}$ to $\mathrm{C}_{18}$ form an equimolar complex (FA/NA) with NA. ${ }^{1}$ The complex can improve hygroscopicity and remove the bitter taste of NA. ${ }^{2}$ We determined the crystal structures of an equimolar complex $\left(\mathrm{C}_{12} / \mathrm{NA},{ }^{3} \mathrm{C}_{17} / \mathrm{NA}^{4}\right.$ and $\left.\mathrm{C}_{18} / \mathrm{NA}^{5}\right)$. The common features of the complex were three types of hydrogen bonds, the conformation of FA and NA molecules and the formation of a lamellar structure. One type forms an equimolar FA/NA complex. Another type forms a dimer of the complex. The other type forms a hydrogen-bond sequence along with lamellar plane. These results lead us to speculate on the structural similarity of the complex from $\mathrm{C}_{13} / \mathrm{NA}$ to $\mathrm{C}_{16} / \mathrm{NA}$ with the complex reported in our previous papers. To confirm the speculation, we investigated the complex of palmitic acid and nicotinamide.

Crystals of an equimolar complex (Fig. 2) of $\mathrm{C}_{16}$ and NA were grown by slow evaporation from an acetone solution at $35^{\circ} \mathrm{C}$. A colorless plate-like crystal measuring $0.7 \times 0.5 \times 0.06 \mathrm{~mm}$ was used for X-ray analysis. Crystal and experimental data are given in Table 1, and the final atomic parameters for the non- $\mathrm{H}$ atoms are listed in Table 2. The structure was solved by direct

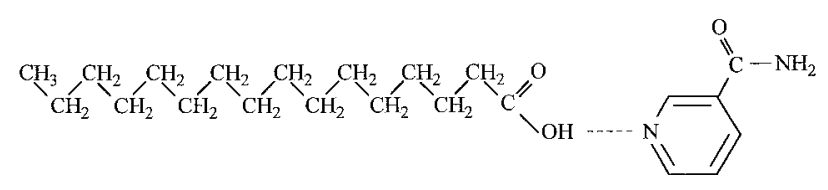

Fig. 1 Chemical structure of the title complex.

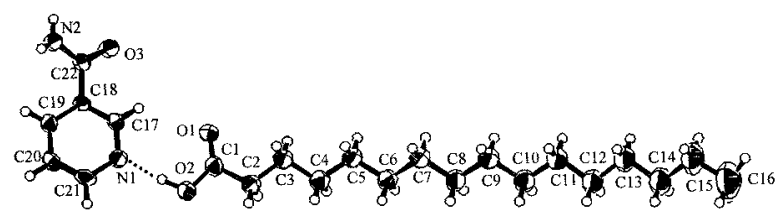

Fig. 2 ORTEP III drawing of the title compound with the atomnumbering scheme. The dotted line indicates a hydrogen bond. Displacement ellipsoids are drawn at the $50 \%$ probability level.

$\doteqdot$ To whom correspondence should be addressed.

E-mail: ueda@hoshi.ac.jp methods (SIR92) ${ }^{6}$ and refined by the full-matrix least squares method. All H-atoms, except for those of the carboxyl, animo and methyl groups, were refined using a riding model. The $\mathrm{H}-$ atoms of the carboxyl, animo and methyl groups were identified from a difference map and refined with an isotropic temperature factor. All calculations were performed using the CrystalStructure crystallographic software package. ${ }^{7}$

The alkyl chain of $\mathrm{C}_{16}$ took an all-trans conformation, as can be seen in Fig. 2, and the hydrogen-bond distance observed between the $\mathrm{N} 1$ atom of the pyridine ring of NA and the $\mathrm{O} 2$ atom of $\mathrm{C}_{16}$ is $2.699(6) \AA$, the angle of $\mathrm{O} 2-\mathrm{H} 1 \cdots \mathrm{N} 1$ is $178.1^{\circ}$. The $\mathrm{O} 3$ and $\mathrm{N} 2$ atoms of the amide group of NA form a hydrogen bond with the $\mathrm{N} 2^{\mathrm{i}}$ and $\mathrm{O} 3^{\mathrm{i}}$ atoms of the amide group of the other NA related by the symmetry operator of (i) $-x,-y$, $-z-1$. The distance of $\mathrm{O} 3 \cdots \mathrm{N} 2^{\mathrm{i}}\left(\mathrm{N} 2 \cdots \mathrm{O}^{\mathrm{i}}\right)$ is $2.948(5) \AA$ and the angle of $\mathrm{O} 3-\mathrm{H} 38 \cdots \mathrm{N} 2^{\mathrm{i}}$ is $172.2^{\circ}$. Because of these hydrogen bonds, the complex forms a dimer, as can be seen in Fig. 3. The

Table 1 Crystal and experimental data

Formula: $\mathrm{C}_{22} \mathrm{H}_{38} \mathrm{~N}_{2} \mathrm{O}_{3}$

Formula weight: 378.55

Crystal system: triclinic

$\begin{array}{ll}\text { Space group: } P \overline{1} & Z=2 \\ a=5.4461(9) \AA & \alpha=90.61(2)^{\circ}\end{array}$

$b=41.627(7) \AA \quad \beta=92.30(2)^{\circ}$

$c=5.042(2) \AA \quad \gamma=91.079(13)^{\circ}$

$V=1141.9(6) \AA^{3}$

$D_{\mathrm{x}}=1.101 \mathrm{~g} / \mathrm{cm}^{3}$

No. of reflections used $=3044$

$2 \theta_{\max }=136.0^{\circ}$ with $\mathrm{Cu} K_{\alpha}$

$R=0.0989 \quad R_{\mathrm{w}}=0.0870$

$(\Delta / \sigma)_{\max }=0.000$

$(\Delta \rho)_{\max }=0.37 \mathrm{e}^{-3}$

$(\Delta \rho)_{\min }=-0.39 \mathrm{e}^{-3}$

Measurement: Rigaku AFC7R

Program system: CrystalStructure 3.7.0

Structure determination: SIR92

Refinement: full matrix

CCDC 292804 contains the supplementary crystallographic data for this paper. These data can be obtained free of charge from The Cambridge Crystallographic Data Centre via www. ccdc.cam.ac.uk/data_request/cif 
Table 2 Atomic coordinates and equivalent thermal parameters for non-hydrogen atom

\begin{tabular}{lllll}
\hline atom & $x$ & $y$ & $z$ & $B_{\text {eq }}\left(\AA^{2}\right)$ \\
\hline O1 & $-0.2670(8)$ & $0.13567(10)$ & $0.0649(9)$ & $5.67(12)$ \\
O2 & $-0.6119(7)$ & $0.15759(9)$ & $-0.0869(8)$ & $4.88(11)$ \\
O3 & $-0.1947(7)$ & $0.02815(9)$ & $-0.3117(7)$ & $3.99(10)$ \\
N1 & $-0.6407(9)$ & $0.10725(11)$ & $-0.4294(9)$ & $3.91(12)$ \\
N2 & $-0.2213(8)$ & $0.01590(10)$ & $-0.7462(8)$ & $3.61(11)$ \\
C1 & $-0.4127(11)$ & $0.15721(13)$ & $0.0681(12)$ & $3.78(14)$ \\
C2 & $-0.4001(11)$ & $0.18504(13)$ & $0.2573(12)$ & $4.43(16)$ \\
C3 & $-0.1507(10)$ & $0.19288(12)$ & $0.3861(12)$ & $4.29(16)$ \\
C4 & $-0.1522(11)$ & $0.22308(12)$ & $0.5573(12)$ & $4.39(16)$ \\
C5 & $0.0958(11)$ & $0.23384(12)$ & $0.6754(13)$ & $4.45(16)$ \\
C6 & $0.0866(11)$ & $0.26398(12)$ & $0.8468(13)$ & $4.44(16)$ \\
C7 & $0.3337(11)$ & $0.27601(13)$ & $0.9584(13)$ & $4.67(17)$ \\
C8 & $0.3221(11)$ & $0.30590(13)$ & $1.1310(13)$ & $4.63(16)$ \\
C9 & $0.5696(11)$ & $0.31809(13)$ & $1.2419(13)$ & $4.90(17)$ \\
C10 & $0.5589(11)$ & $0.34790(13)$ & $1.4157(13)$ & $4.90(17)$ \\
C11 & $0.8070(11)$ & $0.35985(13)$ & $1.5261(14)$ & $5.21(18)$ \\
C12 & $0.7956(12)$ & $0.38984(14)$ & $1.6968(14)$ & $5.38(19)$ \\
C13 & $1.0443(13)$ & $0.40170(16)$ & $1.8068(15)$ & $5.9(2)$ \\
C14 & $1.0351(14)$ & $0.43162(16)$ & $1.9758(16)$ & $6.6(2)$ \\
C15 & $1.2850(16)$ & $0.44345(18)$ & $2.0819(18)$ & $8.7(3)$ \\
C16 & $1.2822(18)$ & $0.47339(19)$ & $2.253(2)$ & $11.6(4)$ \\
C17 & $-0.4776(10)$ & $0.08353(12)$ & $-0.4072(11)$ & $3.70(14)$ \\
C18 & $-0.4743(9)$ & $0.05820(12)$ & $-0.5822(10)$ & $2.96(12)$ \\
C19 & $-0.6495(10)$ & $0.05649(12)$ & $-0.7887(11)$ & $3.49(13)$ \\
C20 & $-0.8199(11)$ & $0.08065(12)$ & $-0.8097(12)$ & $4.04(15)$ \\
C21 & $-0.8111(10)$ & $0.10466(13)$ & $-0.6267(12)$ & $4.04(15)$ \\
C22 & $-0.2864(10)$ & $0.03234(12)$ & $-0.5358(10)$ & $3.01(12)$ \\
\hline
\end{tabular}

$B_{\text {eq }}=8 / 3 \pi^{2}\left[U_{11}\left(a a^{*}\right)^{2}+U_{22}\left(b b^{*}\right)^{2}+U_{33}\left(c c^{*}\right)^{2}+\right.$

$\left.2 U_{12}\left(a a^{*} b b^{*}\right) \cos \gamma+2 U_{13}\left(a a^{*} c c^{*}\right) \cos \beta+2 U_{23}\left(b b^{*} c c^{*}\right) \cos \alpha\right]$

$\mathrm{O} 3$ atom also forms a hydrogen bond with the $\mathrm{N} 2^{\text {ii }}$ atoms related by the symmetry operator of (ii) $x, y, z+1$ and the $\mathrm{N} 2$ forms a hydrogen bond with the $\mathrm{O}^{3 i i}$ atom related by the symmetry operator of (iii) $x, y, z-1$. These hydrogen bonds (distance of $\mathrm{N} 2 \cdots \mathrm{O} 3^{\mathrm{iii}}$ is $2.911(5) \AA$ and angle of $\mathrm{N} 2-\mathrm{H} 37 \cdots \mathrm{O} 3^{\mathrm{iii}}$ is $158.1^{\circ}$ ) form hydrogen-bond sequences along the $c$ axis.

The structure of the title compound forms a lamellar structure in which NA molecules are intercalated in the hydrophilic regions of lipid bilayers composed of $\mathrm{C}_{16}$ molecules (Fig. 3). In the lipid bilayers, the characteristics of the lateral packing of the hydrocarbon chains are usually described by subcells. ${ }^{8}$ The alkyl chains form a monoclinic subcell $\mathrm{M}_{/ /}$with $a_{\mathrm{s}}=4.80 \AA, b_{\mathrm{s}}=$ $4.27 \AA, c_{\mathrm{s}}=2.54 \AA, \gamma_{\mathrm{s}}=113.1^{\circ}$. The amide group in NA is twisted out of the plane of the pyridine ring. The torsion angles N2-C22-C18-C19 and O3-C22-C18-C17 are 28.3(9) and 23(1) respectively.

The characteristics of the crystal structure of the title

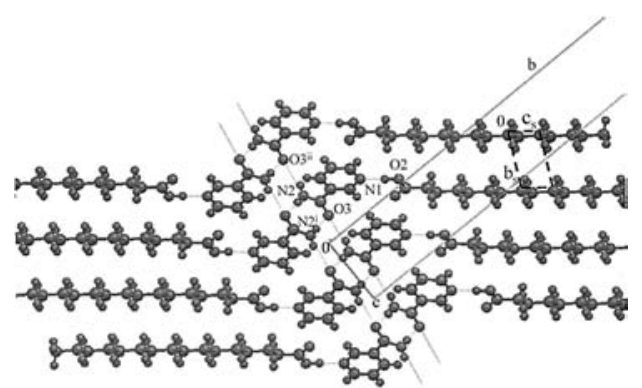

Fig. 3 Intermolecular hydrogen bond (dashed lines) in the crystal structure of the title compound. Projection is along the $a$-axis.

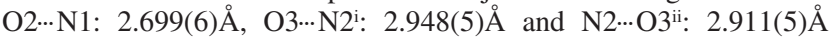
with symmetry operators of (i) $-\mathrm{x},-\mathrm{y},-\mathrm{z}-1$ and (ii) $x, y, z+1$. Subcell projected along the $a_{\mathrm{s}}$-axis is shown by broken lines.

compound, such as the style of hydrogen bond, the conformation of the NA and FA molecules and subcell type of hydrocarbon chains, are very similar to these of the equimolar complex of NA and FA, reported previously.

\section{Acknowledgements}

The authors wish to thank Mr. T. Takayanagi, Mr. Y. Takamiya and Miss M. Toda for skillful assistance in this study.

\section{References}

1. F. Ueda, T. Higashi, Y. Ayukawa, A. Takada, T. Fujie, A. Kaneko, and S. Yokoyama, Bitamin, 1988, 62, 669.

2. Y. Ayukawa, T. Higashi, and F. Ueda, Japanese Patent No. 289078, 1986.

3. D. Chakrabarty, H. Nagase, M. Kamijo, T. Endo, and H. Ueda, Anal. Sci., 2006, 22, x27.

4. M. Amai, M. Kamijo, H. Nagase, T. Endo, and H. Ueda, Anal. Sci., 2005, 21, x9.

5. M. Amai, T. Endo, H. Nagase, H. Ueda, and M. Nakagaki, Acta Cryst., 1998, C54, 1367.

6. A. Altomare, G. Cascarano, C. Giacovazzo, A. Guagliardi, M. Burla, G. Polidori, and M. Camalli, J. Appl. Cryst., 1994, 27, 435.

7. CrystalStructure, version 3.7.0, 2000-2005, Crystal Structure Analysis Package, Rigaku and Rigaku/MSC.

8. S. Abrahamsson, B. Dahlén, H. Löfgren, and I. Pascher, Prog. Chem. Fats Other Lipids, 1978, 16, 125. 